\title{
The Temporalization of Financial Markets: From Network to Flow
}

\author{
Karin Knorr Cetina and Alex Preda
}

$\mathrm{W}$

E ANALYZE here several market configurations and argue that, in the course of their development, at least some markets moved from a network-based architecture to one based on a scopic mode of coordination. In networks, the mechanism of coordination is relational and selective; coordination emerges from passing things through the pipes that link the network nodes. A scopic mechanism, in contrast, works through collecting and 'appresenting' things simultaneously to a large audience of observers. The transformation from relation-seeking actors to data and narratives beamed to observers enabled a flow market to emerge that moves across time zones with the sun. The notion flow points to the streaming character of market reality and some of its consequences. The specialized lifeworld of flow markets is 'metastable' in physicists' sense: it is stable only long enough to enable transactions to occur and changes with transactions.

Trading media and technologies have been significant components of these architecture changes - and these media and technologies also display this architecture to the public in iconic representations of financial markets. In the 18 th and early 19th centuries, market 'technology' consisted of human processing, and human and even animal transmission: brokers received and noted trading interests, couriers dispatched orders and messages, pigeons carried news, dealers traded in back alleys, and all parties gossiped information. In the 21 st century, a historically unprecedented, integrated system of new institutional components, electronic circuits, software, hardware and systematic information processes make up global financial markets. The ticker is somewhat of a transitional object in these architectural changes. On the one hand, it sustained and continued earlier network configurations built into its operation. At the same time, it temporalized the complexity of earlier market transactions by providing 
running price- and volume-histories from which new trades could take their lead. The ticker thus sequentialized and displayed past market activities and can be seen as a first step toward market mediatization. Computer-based scopic systems (see the section on 'Sequencing and Temporalization', p. 130) imply full mediatization - by which we mean the replacement of embodied transaction and transmission capabilities by a set of technological and behaviorally enhancing components that, together, serve as a medium for the globally temporalized performance of these markets. These systems added to the ticker's record of market transactions the capability to perform transactions onscreen, sequentialized current market activities and enabled the referential whole of the market to become interiorized within them - they created a market that is now its own stand-alone world, complete with its own vernacular sociology of this world - all within the scopic medium. In contrast to the material and embodied life-world, however, this market is a collective system generated entirely in a symbolic space - the market world is informational.

This implies another change: today, markets are also knowledge systems. The technologies discussed here are not simply facilitating tools, but means of articulating, exhibiting and ordering the properties of these markets. They enable and include epistemic functions. With the ticker, markets begin to be texted systematically in the form of price recording. When this is combined with archiving and analysis, market knowledge becomes decoupled from personal experience, diary keeping, and the like. Today, scoping media include a multitude of epistemic functions, and they make available unprecedented data streams processed by divisions of analysts, model builders and strategists located on the trading floors of major banks - in an informational world, all relevant matter is pre-coded and recorded in a textual or mathematical language and in this sense is 'readyto-hand' for analysis. Exchanges, too, attract young computer- and analysissavvy professionals who push out earlier and older open outcry brokers and traders (Zaloom, 2006). In short, markets of this sort have become financial systems qua streaming epistemic systems.

What follows is not a straightforward history. We say only little about pre-ticker stock markets (see Preda, 2001a, 2001b), discuss the ticker mainly in relation to stock exchanges, and then move on to currency markets - for one particular reason: it is the currency market that is today the technologically most advanced market. Though stock exchanges have made rapid technological advances in the last years, they are not (yet) globally integrated platforms of trading. Comprehensive computer-based systems developed originally not in stock exchanges, but in over-the-counter markets, notably the foreign exchange market, from the early 1970s. These systems became fully operational there already in 1981 and began to dominate exchanges only 20 years later, at the beginning of the 21 st century. One consequence of early adoption and internal development of computerbased trading in the foreign exchange market is that the latter is now also today's most genuinely global market - and the largest market world-wide, 
with an average daily turnover of US $\$ 1.8$ trillion when it was last surveyed (Bank for International Settlement, 2005). Most stock exchanges were originally national financial centers, insulated from other countries by national regulatory codes, linguistic and geographical communication barriers, and traders' monopolizing strategies. The creation of transcontinental exchanges is something that is taking place in the stock market only as this article is written.

\section{The Pre-ticker Execution Network Market}

Consider trading at the New York Stock Exchange (NYSE) during the time before the late 1860 s/early $1870 \mathrm{~s}$. During this time, two exchanges coexisted in the same building: the Regular Board (which operated on the first floor of the Broad Street building in New York), and the Open Board, which was located on the ground floor of the same building and spilled out into the street. Transactions also took place in the street and throughout the neighborhood. While the Regular Board practiced ritualized trading in sequential form (members traded securities one by one), the Open Board practiced continuous trading. In sequential trading, transactions in one stock had to be closed before transactions in the next stock could begin. The price for a given stock at closing could serve as a point of orientation for the opening price when the next sequence of trading this stock began, usually on the next day of trading. In continuous trading, transactions in several stocks took place simultaneously, and prices changed several times during the trading day. One and the same security might be traded by groups on the Open Board, and on the Regular Board (e.g. Eames, 1894: 51-7; Medbery, 1870: 39; Smith, 1871: 76-7). The Regular Board recorded 'indicative' prices on a blackboard. The Open Board paid agents to listen at the boardroom's keyhole and to go and tell the prices and transactions they overheard to market actors on the ground floor and in the street (Clews, 1888: 8). Brokerage houses employed courier boys to transmit price infor mation and orders to and from the brokerage office and its brokers on the floor of the Open Board (Downey, 2000: 132-3). Price information and orders were written down on paper slips by brokers on the floor and handed over to courier boys, who ran to the brokerage house and brought back transaction orders, also written on paper slips. Price data recorded on some paper slips represented past real transactions, but this information was not accessible to outsiders. It remained private, circulating only between floorbrokers and their headquarters. Observable (to all members of the Regular Board) were only the indicative prices established by the Board, which acted as the central node of a networked system.

The system was marred by high degrees of uncertainty on several levels. For example, questions of 'Who?', 'What?' and 'How much?' occurred frequently in relation to who the transacting parties were and what they were trading. But the answer to these questions depended on the answer to further questions such as: 'Where is the slip of paper?' 'Where is the courier boy?' 'What happened with security A in various groups on the Open 
Board when the Regular Board ceased trading it for the day?' In other words, transaction-related uncertainties could not be processed if one did not first deal with the uncertainties associated with the embodied recording and transmission technology of the time.

The transatlantic telegraph was inaugurated in 1865 but, due to its costs, among other reasons, was only sparingly used and did not reduce all technological uncertainties. Some of these resulted from the repeated coding and decoding of messages that the telegraph necessitated. At the transmit $\neg$ ting end, a Morse operator coded the message; at the receiving end, another Morse operator decoded it. This took time and required two skilled, wellpaid mediators between the machine and its observers. It also included the risk of misinterpretation: one or two dots missed by the decoding operator, and the message could become a completely different one. The boundary between the Regular Board and the Open Board also increased uncertainties, since information on the Open Board was based on eavesdropping and rumor about Regular Board transactions. The persistent uncertainties about prices and the identity of traded securities made it difficult to produce itemized and continuous price data sequences - to our knowledge, there is no record of such data sequences from the pre-ticker period. The whole configuration was a networked system focused on the execution of exchange. The network managed the information and order transfer, as well the un $\neg$ certainties mentioned, by cultivating, maintaining and reinforcing relation ships between brokerage houses and floor traders within the internal boundaries between the Regular and the Open Boards.

We distinguish such execution networks from transaction networks which existed in pre-computer over-the-counter trading (see the section 'From Networks to Scopes', p. 131). Transaction networks link agents who trade with one another across space without the service of exchanges. Such networks were characteristic of the foreign exchange market before the $1980 \mathrm{~s}$; in this area, market makers went through relational ties to solve the problem of identifying buyers and sellers and of finding prices. Exchangebased markets, in contrast, solve this problem through the exchange itself - by bringing buyers and sellers (or their representatives) together in a physical place where diverse interests can find their match (see Knorr Cetina, 2005). Yet such systems of representing interests and brokering matches create their own execution problems, as indicated before. And some of the uncertainties of such systems depend on the properties of the network - on who occupies the nodes and how well transmission lines work.

\section{Ticker Transactions and the Temporalization of Information}

The stock ticker was introduced on the NYSE in 1867 and was later supplemented by the telephone (in 1878), cinema-like screens (in the $1920 \mathrm{~s}$ ) and other devices. The ticker worked as an electromagnetic tele $\neg$ graph that printed out letters and figures rather than Morse signs. It was thus cheaper to operate, requiring just one Morse operator. Data could be read directly from the tape, whereas the Morse telegraph required decoding, 
transcription and transfer of the message. The sending end (on the floor of the NYSE) of the ticker was manned by the operator who sent messages using Morse signals. These signals were automatically transformed at the receiving end into letters and numbers (Calahan, 1901). The receiving side had two options: it could either just observe the flow of data, or respond to them by sending orders back to the floor brokers. A customer walking into a brokerage house wanting to send an order went to the order desk and placed the order with a clerk, who could (a) send a courier, or (b) place a phone call, or (c) telegraph back to the floor. Couriers could be bribed and phone lines tapped, so that coded telegrams seemed the best alternative. Figure 1 illustrates this system of communication.

The new system gave stability to the network channels or 'pipes' (Podolny, 2001) through which data traveled. The ticker also allowed for a redrawing of boundaries that determined access to price data. This helped externalize some earlier uncertainties; yet other uncertainties continued to haunt participants.

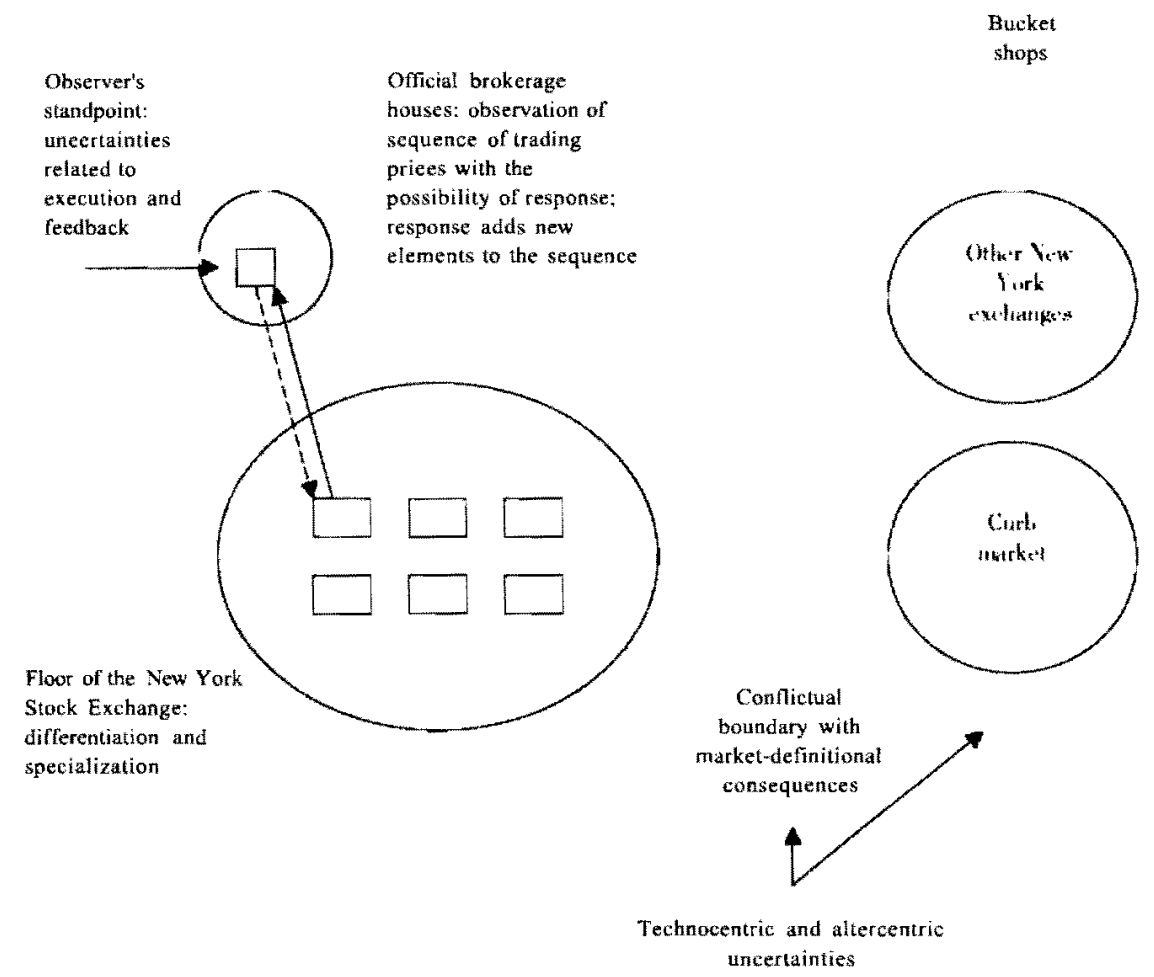

Figure $I$ The externalizing network system: uncertainties are transformed within the system and transferred to its external boundary 
Consider first the new institutional boundaries that were established between the NYSE and other Manhattan-based exchanges (e.g. the Consolidated Stock and Petroleum Exchange) with respect to accessing stock ticker price data. After the introduction of the stock ticker, the Regular and Open Board merged. As this internal boundary disappeared, external ones were created. Observers of financial transactions became restricted to the visitors' gallery, from which the exchange activities appeared only as a rumble and jumble of people. Controls over the networking system were imposed and access from the outside was made difficult. The NYSE systematically attempted to control price data and to forbid other stock exchanges from installing tickers. These tried to circumvent the restrictions, or abstained from using ticker data (e.g. Pratt, 1903: 134; Selden, 1917: 158; Wyckoff, 1930: 23). The London Stock Exchange implemented similar measures in its handling of ticker-generated data - it supplied only incomplete data as a way of maintaining a monopoly over its business (e.g. Eames, 1894: 65, 91 ; Gibson, $1889: 83$ ).

Status boundaries also mattered. There were long and acrimonious fights between official brokerage houses and bucket shops with regard to access to price data. Bucket shops were decidedly less respectable than official brokerage houses. They tried to gain access to ticker prices either by exploiting the telegraph companies' drive to acquire new customers or, when stock exchanges concluded exclusive contracts with telegraph companies, by tapping into the wires of the stock exchange. Some broker ages also chose to install false tickers in order to signal respectability and to attract new clients (Cowing, 1965: 103; Fabian, 1990: 191). The fights diminished only after a Supreme Court Decision in 1905 in the case of Chicago Board of Trade (CBOT) v. Christie Grain \& Co. (198 US 236), the latter being a bucket shop that had tapped into the telegraph wires of CBOT. The Court recognized the data as being owned by the CBOT, but it also recognized them as being fraught with public use, a definition which, in time, gave regulators access to price data and opened new legal possibilities for regulatory intervention into financial transactions."

The limits on access thus externalized some uncertainties - actors outside the network now had less or no access to the system's price infor mation and relationships. This once again reinforced the network character of the market. The system continued to suffer from other uncertainties, most importantly those related to execution time and feedback. The ticker recorded all transactions, ${ }^{5}$ but this did not mean that all transactions could be executed immediately after being placed, or that they were immediately recorded - there remained a significant difference between private communication (the broker being told that his order had been filled) and formal confirmation (the executed order appearing on the ticker tape), as a broker from an NYSE member firm suggests:

Well, this was 1959 , actually. So I went up and I went to Boston and I got a job as a, as a broker. Going back to, to show you the illustration of what 
happens - how, how did we put orders in that, those days, uh, you would speak to somebody. They would say, well, let's buy 300 shares of Boeing Aircraft. It - they only had tr - traded then like 5 million shares or 2 million or 3 million shares during the course of the day. You would go to the back, there was no electronic means, go back, and give it to a telegraph operator and he would type it in to the telegraph in the New York office and then it would go, then go down to the floor of the exchange, and they would walk over to the posts where the order was being executed. So it took a long time. There were no instantaneous kinds of things. Then you had to wait quite a while till they got that information back to you. Again, they would telegraph it back, get [it] up to you and so, you would never know. In 1962 [sic], when, uh, John F. Kennedy was assassinated, I had a client who wanted to sell 500 shares of Boeing at that time. [. . . And so we placed the order in about 2 o'clock in the afternoon [. . .] before the market had closed down, and I waited. Three o'clock, four o'clock, five o'clock, I st - continued to wait. And at 8:15, I saw 500 shares - at night, pm - same day - I saw 500 shares of Boeing trade at the price that, $\mathrm{uh}, \mathrm{I}$ had been told it was sold at. And so, here I was, 6 hours after the order was placed... (Interview B1, May 2006)

This situation continued until orders began to be transmitted by computer in the 1990s, as the same broker (talking to another broker on the phone about how trading was done in the earlier days) describes:

In the ' 90 s we went to the computer, right, but was there any time in the ' $80 \mathrm{~s}$ that you can remember that you placed orders through a computer or did it yourself, or did you always call it in or write it out and give it to somebody? [...] Mmhmm, that's ... you give, you gave it to - you gave it to the order room, and the order room typed it in, or telegraphed it, or something like that. So, the first time you can remember actually placing it on the computer was in, in Europe? In Shields, when you went, switched over in the early '90s ... right. [. . .] Even at Shields, you didn't do it? [. . ] Yeah, but a big order like that ... well, you would wa - yeah, and block-wise, you still did by phone, but, but then you started doing, maybe smaller orders . . . right. [ . . ] [talking to the interviewer AP now] So, he, uh, he had a client, a very big client who, uh, was involved with the, one of the research, uh, services, and then he went and started his own hedge fund, or he started his own, uh, managed fund, and, and he would have 20,000 share orders and 8,000 , and we used to call those in. He did it by phone. Uh, otherwise, we, he continued to give it to the, the telegraph kind of, uh, some means of, of transmitting it by print to the trader. Now, it would come in, the orders would come into the floor of the exchange so that ... we had a booth down there and we would have, uh, the orders came to our booth right on the floor of the exchange, and they would write it up and give it to one of our, uh, floor traders who would then run over to the post and then, and he would hand them the order. So it was very labor intensive, from that standpoint. (Interview BI, May 2006)

This execution network implied time lags between placing transactions and their visual confirmation. It also prompted a differentiation in terms of trust, corresponding to the heterogeneity of communication technologies; for 
example, technologies of personal communication (phone calls for bigger orders) may have been preferred over the impersonality of the telegraph. With their different labor intensity (e.g. sending messengers across the floor), uncoordinated rhythms, bodily requirements and trust indexes, these technologies further enhanced networking needs.

\section{Sequencing and Temporalization: A Running System and its Epistemic Payoff}

With extensions, modifications and upgradings" this networked system remained in place in securities markets into the 1980s and 1990s (e.g. Zaloom, 2006: 8-9). Structural change only came with what we shall call the scopic form of coordination and onscreen trading. The ticker initiated a trend that pre-cast some aspects of scopic systems: it sequentialized the market, initiating a price-and-volume flow that became at the same time an information flow. An investor active on the NYSE since the 1960s describes here the running ticker data:

$A P$ : How could you then see the tape in the broker's office?

II: If we were sitting here in the office and the desk was here - [points toward corner of the office] It would be off - there would be a lot of - the whole room, right? And usually across one wall you'd have, uh, electronic tape. It wouldn't be, you know - I never was in the market where you had the old, you know, machine things. But from the very beginning technology you did have -

$A P$ : These electronic tapes. [. . .] On one wall.

II: Yeah, yeah, like Times Square. The big thing. Okay, running across. Two lines, right? Uh, prices. And you could get the speed idea. And it was live. It was a live tape, you know, going through, and you could watch it ... and that was important, because you did get a good rhythm, you know, even better than now in some ways. The running tape, people often used to get upset when it disappeared into the computer screens, because you knew, for example, when the volume would pick up because they would go shorthand on the tape, and the volume figure's a nice drop down. I mean, you got a great flow. Okay, and you could see how often, if you were looking let's say, at IBM, and you want to see how often it came up, right? You get a flavor also of the price differentials, who is keeping tight markets. Uh, you could see shorts, which was very important. (Interview, January 2006)

The ticker recorded price data that represented real, past transactions - though not necessarily immediate past transaction. For any securities A, $\mathrm{B}, \mathrm{C} \ldots \mathrm{N}$, with the price $\mathrm{x}$ and quantity $\mathrm{y}$, at $\mathrm{t}=1,2,3 \ldots \mathrm{n}$, the price data sequence looked as follows:
A 1 B1 B2 A2
C1
A3
$\mathrm{C} 2$
B3 ... Nn
$x|y 1 \quad x| y 1 \quad x 2 y 2 \quad x 2 y 2$
$x 3 y 3 \quad x 2 y 2 \quad x 3 y 3 \ldots x y$. 
First, the sequence provided a material and itemized market memory. In fact, since sequences started afresh each day, at the end of a trading day the ticker tape in its full length was the market days memory. The tape differed from previous price lists that had provided only opening and closing prices (and some lows and highs) in that it itemized all past transaction prices and volumes.' Second, the tape was an information source: it could be scrolled through, prices at different times could be compared and inferences about market movements could be made. Thus, the sequences formed the basis for epistemic practices focused upon ticker information. Third, brokerage houses produced new data sequences from the tapes. They employed specialized clerks who sat by the machine picking out prices of individual securities and tabulating their prices and transaction volumes at different times. In other words, they created security-specific data sequences of the form $\mathrm{N} 1 \mathrm{x}$ iy $\mathrm{i}, \mathrm{N} 2 \mathrm{x}_{2} \mathrm{y} 2 \ldots \mathrm{Nnx} \mathrm{y}_{\mathrm{n}}$ - meaning security $\mathrm{N}$ was transacted at price $x$ and quantity $y$ at time 1 , then at price 2 and quantity 2 at time 2 , and so on. Such sequences could then be further tabulated in the form of daily, weekly and monthly charts of price variations."

A running record emerged that visualized the market continuously. When the record was rearranged into analytical, security-specific price and volume sequences, the market for a particular security could be made visible as an abstract aggregate tied to, and yet different from, the multitude of market actors trading the respective security. Re-arrangements suggested new interpretations, comparisons and classifications. In other words, they suggested new epistemic functions. The running ticker data began to turn into a streaming epistemic system. An indication of this that we cannot pursue within the limits of this article (but see Preda, 2007) is the emergence of a specialized group of analysts who began to control these functions. Relatively shortly after the introduction of the stock ticker, around 1900, several brokers from the East Coast (who knew each other) switched from trading securities to interpreting price charts, claiming that this special knowledge could not be properly had from brokers. While it would take some time until technical analysis emerged as a fully fledged profession, its beginnings can be seen in the profession of tape-reading clerks who helped chart prices into systematic information.

\section{From Networks to Scopes: The Foreign Exchange Market}

How do these features fare in contemporary market configurations?" First, instead of the ticker we find scopic media and modes of coordination (see p. 133). Institutional traders still draw on small networks of relationships for information and other purposes, but these are not central to trading execution or transactions. Price and volume uncertainties, as well as delays in execution and coordination problems between technologies, have been virtually eliminated with computerized scopic systems. When buying and selling can be done onscreen and at the click of the mouse, the input (previ $\neg$ ously the order) and output (previously the execution and its documentation) become identical and nearly simultaneous occurrences. There are still sharp 
distinctions between the inside and the outside of the market based on access to trading and information systems. Up to now, access to the most developed Reuters trading systems and global intranets in over-the-counter trading has been limited to certain banks, and inter-bank trading is limited to accredited banks. Though these boundaries begin to blur (e.g. more elec tronic systems have become available to private investors and day-traders), there are still crucial informational and other advantages for the 'insiders' to these systems. Information is streamed as live or near-live coverage of the social world on traders' screens, where it becomes visually attached to the main stream of dealing prices and transactions which, for participants, also are information. We claim that the new features associated with the scopic mode of coordination account for a paradigm shift in market architecture.

Imagine the trading floor of a large investment bank in one of the world's global financial cities. You may see between 200 (Zurich) and 800 (New York) traders engaged in stock, bond and currency trading involving various trading techniques and instruments. Up to 20 percent of the traders may deal in the foreign exchange market, at desks grouped together on the floor (see also Abolafia, 1996; Hertz, 1998; Smith, 1999; Swedberg, 2003; White, 2002; Zaloom, 2006). The traders on these desks in inter-bank currency markets are market makers. They take their own 'positions' in the market in trying to gain from price differences while also offering trades to other market participants, thereby bringing liquidity to the market and sustaining it - if necessary, by trading against their own position. Foreign exchange deals through these channels start in the order of several hundred thousand dollars per transaction, going up to a hundred million dollars and more. The deals are made by investors, speculators, financial managers, central bankers and others who want to profit from expected currency moves, or who need currencies to help them enter or exit transnational investments (e.g. in mergers and acquisitions). In doing deals, all traders on the floors have a technological set at their disposal; most conspicuously, the up to five and more computer screens that display the market and serve to conduct trading. In the morning, traders strap themselves to their seats, figuratively speaking, they bring up their screens, and from then on their eyes will be glued to these screens, their regard captured by it even when they talk or shout to each other, their bodies and the screen world melting together in what appears to be a total immersion in the action in which they are taking part. The market composes itself in these produced-and-analyzed displays to which traders are attached (see Figure 2; for further ethnographic detail, see Bruegger, 1999; Knorr Cetina and Bruegger, 2002).

The assemblage of hardware, software and information feeds that traders work with challenges concepts of contemporary information tech nologies as implying network structures and network society notions (e.g. Castells, 1996): the systems involved are scoping rather than networking systems (Knorr Cetina, 2003), a term that foregrounds the presentational and reflexive capacities of some media that the relational vocabulary does 


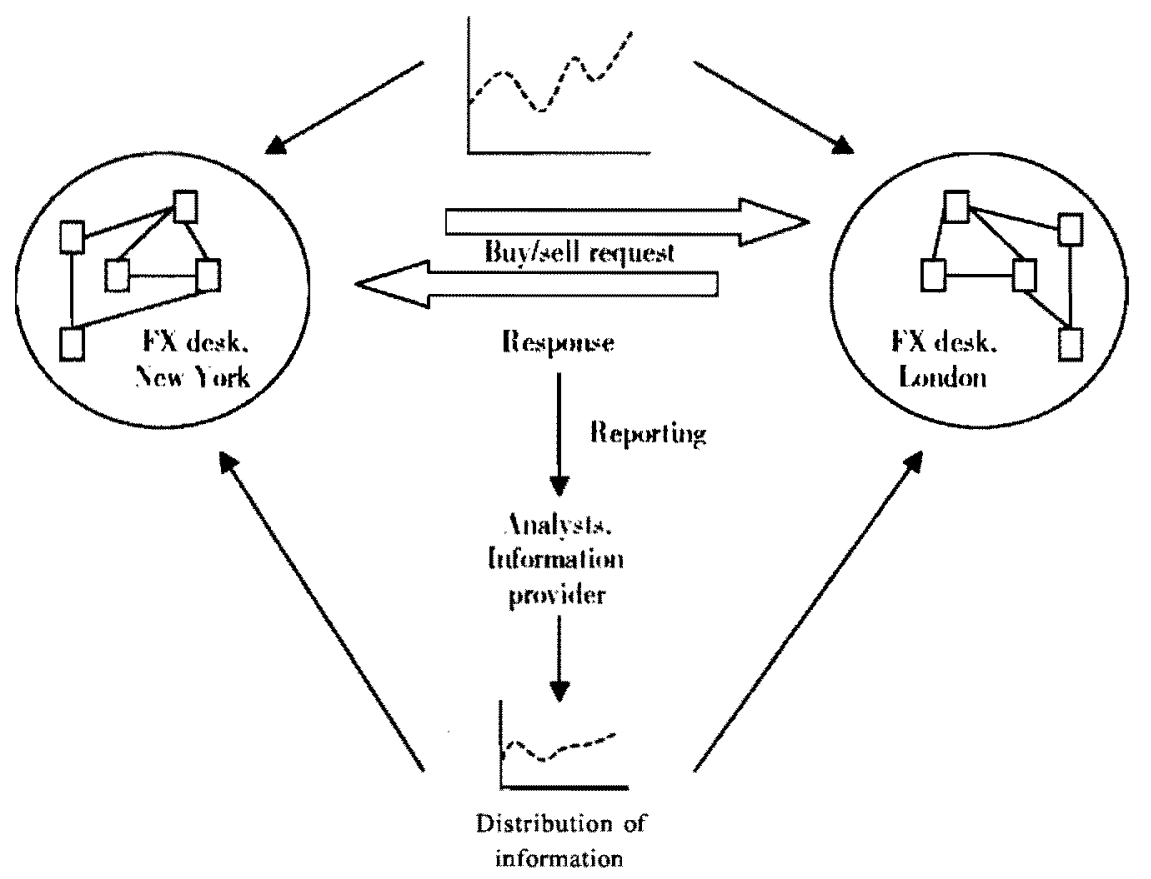

Figure 2 Schematic rendering of inter-bank currency market: traders on trading floors of global cities trade with one another on screen, with the results becoming integrated into charts and market reports available to traders

not capture. In networks, coordination works relationship-by-relationship and node-by-node: relationships need to be established and maintained, information passes through relationships and is limited to them - hence the time lags, trust-needs and opacity of networks. There is no superordinate mechanism that reflects all the information in a network and makes it available simultaneously to all concerned." A scoping system, in contrast, can be defined as a system of observation and projection that assembles on one surface dispersed and diverse activities, interpretations and representations which in turn orient and constrain the response of an audience. A scope, derived from the Greek 'scopein' to see, when combined with a qualifying notion, is an instrument for seeing or observing, as in 'periscope'. Like an array of crystals acting as lenses that collect light, focusing it on one point, such mechanisms collect and focus activities, interests and events on one surface, from whence the result may then be projected again in different directions. When such a mechanism is in place, coordination and activities respond to the projected reality to which participants become oriented. The system acts as a centering and mediating device through which things pass and from which they flow forward. In the present case, the reflexive mechanism and 'projection plane' is the computer screen; along with the screen come software and hardware systems that offer a vast range of observation, 
presentation and interaction capabilities sustained by information and service provider firms. Given these affordances, the pre-reflexive reality is cut off and replaced; some of the mechanisms that we take for granted in a life-world, for example its performative transaction possibilities, have been integrated into the systems, while others have been replaced by specialized processes that feed the screen. The technical systems gather up a life-world while simultaneously projecting it. In the case of the foreign exchange market, they also 'appresent' (Schutz and Luckmann, 1973: 11) and project layers of context and horizons that are out of reach in ordinary life-worlds - they deliver not only transnational situations, but a global world spanning all major time zones (see also Leyshon and Thrift, 1997; Sassen, 2001 : ch. 7). The configuration of screens, capabilities and contents, and their supplying actors, make up a global scoping medium that allows participants to simultaneously confront the market and to be part of it - to be financially positioned in the market, to contribute to it and to feed it with information.

\section{How Did the Market get Onscreen? The Move Away from Transaction Networks}

In the 1970s, first the USA (1971), then major European countries, including Britain by 1979, and finally Japan in the early $1980 \mathrm{~s}$, abolished exchange controls, effectively eliminating the Bretton Woods Agreement in place since 1944 and allowing foreign exchange trading for purposes of speculation. At the time, the most important trading technologies were the telephone, the ticker, which churned out '50 meters a day' (German in original) of news headlines and price pointers and calculators. Activities on the floor centered around 'finding the market', that is finding out what the price of a currency was and who wanted to deal. The market lay hidden in geographical space, and traders relied on networks of relationships in finding and negotiating the market. In the following quote, a former chief of trading recalls how he continually chased after the market:

P: [. . ] So you had to constantly find out what the rates were in countries.

$K K$ : And you did this by calling up banks?

$P$ : By, yes. And there were also calls on the telex by other banks who either wanted to trade or wanted to know, simply wanted to know where dollar-Swiss was. The prices were written down by hand on big sheets of paper which were displayed on wall boards.

In a very real sense, then, dealing was a matter of establishing and using network connections. The networks involved were, however, transaction rather than execution networks - dealing took place between the nodes of these networks, and network connections were maintained through participants trading and sharing information. In contrast, dealing remained extra neous to the execution networks that characterized pre-ticker and ticker 
trading in exchanges (see earlier section 'Ticker Transactions and the Temporalization of Information', p. 126) At the root of our notion of a market arguably lies the idea that the market is a mechanism that solves the problem of bringing together the diverse and dispersed interests of buyers and sellers, of those who dispose of a good and those who need or want it (Knorr Cetina, 2005). With exchanges, this mechanism is that of a specified place in which buyers and sellers of a security can find each other and engage in price adjustments until deals are made. The situation needs to be distinguished from dealing outside central places that widened already during the 16 th century in the expanded space of international trade. This generalized and more private trade is also what lay at the core of preelectronic currency markets discussed here. As 'over-the-counter' markets, they were not based in exchanges - and trading relied on networks of relationships for price- and interest-finding. This situation changed when the market moved onscreen and the scopic form of coordination emerged.

A partial attempt at making markets present in a scopic fashion occurred before the introduction of screens: the prices written down by hand on the 'big sheets' to which P. refers in the earlier quote were displayed on wall boards. When screens appeared, they were at first no more than substi tutes for the 'big sheets': displays on which the handwritten price sheets put together by female clerks were projected on the basis of pictures taken of the sheets on the floor. This form of presentation rested upon a chain of activities that was, in important respects, indistinguishable from the one that led to prices in pre-screen times: it involved narrowing down where the market was by calling up or telexing banks, writing down the responses by hand (and perhaps recalculating prices in national currencies), and making this information available for internal purposes through a form of central, scopic presentation. All this changed when Reuters developed 'Monitor', a computerized foreign exchange system which became the basis for this elec tronic market (Read, 1992: ch. 12). Reuters had perceived the uptake in volumes of trading as an opportunity to expand more strongly into the financial service area and take advantage of the large international infrastructure it had put together for the purpose of transmitting news between continents and countries." In 1964, Reuters teamed up with the Ultronic Systems Corporation of New Jersey, which had developed a computerized stock-quoting system called Stockmaster. The idea behind Stockmaster illustrates not only what the first electronic scoping technologies after the 'big sheets' implied, but also how the ticker became replaced in stock exchanges: Ultronic 'absorbed' ticker-tape signals from all major stock exchanges and other markets by feeding them into master computers that processed the material and relayed it to subsidiary computers and finally to the offices of brokers. As a step towards global scoping, ${ }^{12}$ the system made over 10,000 stock and commodity prices available to brokers on small deskunits (originally teleprinters, later displays on screen) at the push of a button (Muniesa, 2000; Read, 1992: 296-7). Monitor's design was based on the notion of installing computer terminals in the trading units of banks, on 
which traders were able to insert their foreign exchange rates into the system directly, thus making them available at the push of a button instantaneously to everyone connected to the system. It was a reflexive system that relied on the contribution of participants in constructing a central market and in allowing it to operate at instantaneous speed.

Initially, Monitor only provided 'indicative' prices, upon which one could not trade directly. It did, however, from the beginning, augment and contextualize market prices by including news. Actual dealing remained extraneous to screen activities and was conducted over the phone and telex until 1981, when a new Reuters system (including dealing services) went live to 145 institutional customers in nine countries. Within a year, it was extended to Hong Kong, Singapore and the Middle East, resulting in a market with a world-wide presence (Read, 1992: 283ff, 310-11). Reuters knew of course that for any system to be effective in the forex (foreign exchange) market it had to be available transnationally to all major players and, if it was to make dealers' contributed data available and be used for actual trading, it had to link these players. Its project of becoming a financial service provider for this market was based on the awareness that a well-established news agency that had access to exclusive (not publicly available) information transmission lines might be well positioned to stitch together this market and sell to it the political and other information it routinely collected.

Contemporary foreign exchange trading systems (e.g. 'Reuters 3000') are now based on a much further developed version of the original Monitor that includes other subsystems." With the inclusion of dealing services and the more recent development of electronic broker systems (Reuters provides its own), these markets appear fully scoped, that is presented and contextualized onscreen to such a degree that dealing can now proceed without extraneous means. With the help of the deliberate deregulation of these markets by relevant nation-states, they also became disembedded from national political and economic variables and concerns.

\section{The Market as Flow}

The notion of flow as used here is not to be understood metaphorically. Though we cannot provide a detailed analysis of the concept within the space of this article (see Knorr Cetina, 2003 and 2007 for a fuller argument), we can at least point to some characteristics and subprocesses. The defining characteristic is that flow refers to the level of reality itself, which we claim has been temporalized and streamed. To explain this further we start out with the distinctions between the flow reality and everyday reality, as well as other notions of flow. We then address aspects of the structure of experience relevant to flow; we suggest how the ontological fluidity of such a reality is matched by modes of coping and affectivity that ground the reflex-like performances of market action. Third, we ask how flows are organized on the level of institutional interaction in the markets studied. Fourth, we discuss the market in the aggregate as another 
level of flow: its movement across time zones with the sun, that is, with the working hours of traders.

Consider first the ontological fluidity of market reality that contrasts with our notion of an everyday reality. The latter is a spatial concept. We see reality as a spatial environment that exists independently of us and in which we dwell and perform our activities. The notion of a world onscreen also suggest spatiality; it suggests that the idea of a spatial environment can be extended to electronic domains as these become - for some of us - a place to work and live. The problem with these notions in regard to time is that they imply that time is something that passes in these spatial environ ments but is extraneous to the environment itself. We relate the existence of a life-world, of an environment, or of everyday reality more to the physical materiality of a spatial world than to any temporal dimension. We also express, one assumes, the durability of the physical world through spatial concepts. The point is that the screen reality discussed is inherently in flux and has none of this durability. Traders perform their activities in a moving field constituted by changing dealing prices, shifting trading interests the indicative prices), scrolling records of the immediate past that are continually updated, incoming conversational requests, newly projected market trends, and emerging and disappearing headline news, commentaries and economic analyses. They perform their activities in a streaming, temporal world; as the information scrolls down the screens and is replaced by new information, a new market reality continually projects itself. The constantly emerging lines of text at times repeat the disappearing ones, but they also add to them and replace them, updating the reality in which traders move. The flow of the market reflects the corresponding stream of activities and things: a dispersed mass of market participants continues to act, events continue to occur, politicians decide and decisions have effects. Markets are objects of observation and analysis because they change continually; and while they are clearly defined in terms of prices, news, relevant economic indicators and so on at any given moment, they are ill-defined with respect to the direction they will take at the next moment and in the less immediate future.

It is this ontological fluidity of market reality that we want to capture with the notion of flow. The screen reality, in these markets, is like a carpet of which small sections are woven and at the same time rolled out in front of us. The carpet grounds experience; we can step on it, and change our positioning on it. But this carpet only composes itself as it is rolled out; the spatial illusions it affords hide the intrinsic temporality of the fact that its threads (the lines of text appearing on screen) are woven into the carpet only as we step on it and unravel again behind our back (the lines are updated and disappear). As the carpet is woven it assumes different patterns; the weave provides specific response slots to which traders react, taking the patterns in different directions. In other words, the screen reality - the carpet - is a process, but it is not simply like a river that flows in the sense of an identical mass of water transferring itself from one location to 
another. Rather, it is processual in the sense of an infinite succession of nonidentical matter projecting itself forward as changing screen.

Common notions of flow in the social sciences emphasize traveling (Urry, 2000: 15-16, 36-7). The notion allows that it may not just be people that commute, travel and migrate in increasing numbers, but that messages and information also move. In currency trading, financial transactions do not involve physical transfers of money; payments are made through adjust $\neg$ ments of accounts. What 'travels' are communications (payment requests) and financial power as an abstract capacity. Another meaning of flow in the literature is that of fluidity; it draws on the distinction between liquids and solids. Social scientists who emphasize fluidity conceptualize the current stage of modernity as marked by a transition from more solid forms of order and tradition to structures that are more liquid and fluid, or that are melting, as in Marx's famous phrase that 'all that is solid melts into air' (e.g. Bauman, 2000; Berman, 1982). This comes close to the notion of flow used in this article, but the point about the screen reality as a flow is not that it is nomadic (without itinerary) and unmarked by the traces of social and economic structure. The point is the projection and reconstitution of this reality as one that is composite and continually emerging in a piecemeal fashion. To return to the previous metaphor, it is the emergence of the carpet in episodic pieces contemporaneously with the agent's activity and the short reach of the weave that the notion of a flow as used here captures. The screen that rolls out the life-world in which traders move nonetheless constitutes a complex environment composed of 'walkable' regions and of horizons that ground activities. The ground may be shifting continually and the life-world is 'in flight'. But traders are able to deal with this flux; their ways of 'inhab iting' it are adapted to the time-world they confront.

Let us ask, then, how traders deal with the flux; this allows us to move from the level of market reality to that of the structure of experience. Traders expectedly are well aware of the fluidity of markets and define it accord ingly as a life-form (native term) that continuously changes shape, as the following proprietary trader suggests:

$K K$ : I want to come back to the market, what the market is for you. Does it have a particular shape?

$L G$ : No, it changes 'shape' all the time.

Awareness implies adaptation: recall how the running ticker tape changed participants' behavior (see earlier section on 'Ticker Transactions and the Temporalization of Information', p. 126). The tape was experienced as 'live'; its itemized visualization of market transactions required observation and the new clerical tasks of tape watching and data tabulation. The data streams delivered by scopic systems are equally alive; but now the tickers' bare price-volume record of past transactions has evolved into a Bergsonian multiplicity of 'everything' relevant to the market," as indicated before. 
Observing the screen has become a core activity that defines traders' expert work - it is a full-time task in which everyone present on trading floors (supervisors and analysts included) is engaged. Watching the market involves modes of affectivity that we want to call intensity and preparedness. Intensity is defined here as the physical connectedness traders feel with the market. Though traders are not able to slip through the screen and walk into the 'life-form' of the market, they stand within its intimate space - close enough to feel every 'tick' of its movements, and to tremble and shake whenever it trembles and shakes. Observation is often seen as a distanced and distantiating activity, but intensity points in the opposite direction." Watching the market intensely (and analyzing what one watches) is also an analytically distinct stream of activities that results in preparedness - the readiness to respond reflex-like to trading challenges that appear onscreen. Traders' translation of their way of responding to the market is to say that they trade 'by the seat of their pants' and based on a 'feeling for the market'. The simultaneous progress of two distinct streams of activities, trading and observing the market, enables a mode of coping specifically adapted to fluidity and rapid changes. Observing the market means preparation and tuning in: the trader can spring into action fast and 'unthinkingly' when prompted. Trading then conforms more to Mead's model of a conversation of gestures than to models of deliberation and calculation. Understanding speculative behavior requires, we claim, that we move away from the decision-making frameworks that dominate the economic and some of the sociological literature on market hehavior. In currency spot transactions, trading tends to be a form of informed tracing - a form of following and anticipating the flow, grounded more in a structure of feeling than in modes of calculation.

The third consequence we want to point out refers to the institutional formats within which trading proceeds. So far we have characterized a flow reality in terms of its ontological fluidity and multiplicity. This multiplicity is not chaotic or marked by an undefined heterogeneity. Rather, flows are composed of streams and sub-streams of transactional episodes within which unfolds the multiplicity of events. A characteristic feature of these streams is their sequential presentation and interaction formats. Scoping systems include sequencing automats such as electronic broker systems that press incoming demands of dispersed geographical origin into a temporal, sequential order. They include conversation capabilities that offer the sequential format of everyday talk for the purpose of dealing and information conversations. They offer many forms of sequential records, bulletin boards, etc. Traders also construct their own sequences as they move from one screen section to another, taking into account different transaction streams and records. Sequencing, then, is the main mechanism that turns a spatial networkscape into a temporal world. Wide-range sequencing is both enabled and required by scoping media. Instead of leaving things where they originate, nested and hidden in vast geographical space, they collect and project them on small globally shared surfaces (traders' screens). Streaming things 
one after the other would appear to be a major tool in accomplishing the task.

At the center of trading is the electronic broker (EBS), a sequence generator for the market flow. The system sorts incoming orders automatically according to best buy and sell prices, which it displays, while keeping the sequentially next-to-best orders on internal record (see Knorr Cetina, 2007 for details). The advent of the stock ticker sequentialized the parallel transaction activities of previous exchanges. It reduced the complexity of previous entangled and parallel trading systems by instituting at the center of trading a running price list that presented the market through its previous deals. Electronic broker systems combine the transaction-recording capacities of the ticker with parts of what live brokers do in open-outcry exchanges - the system presents trading interests at the globally best price, to which traders respond by buying or selling according to their interests. What results is a global series of trades and price changes that forms the core of the foreign exchange market (approximately 80 percent of deals are part of this stream according to participants). A second trading stream runs through the 'conversational dealing', a system that allows participants to buy and sell within electronically mediated conversations they conduct with one another. As exchanges of texted questions and answers, trading conversa $\neg$ tions add more strings to the flow - strings of conversations that float in the electronic medium of the market. A third stream consists of information conversations and personal talk - also conducted through conversational dealing windows, but distinct from dealing sequences in terms of conver sational structure and institutional restrictions." There are more streams for example, bulletin boards allow sequential postings of insider observa $\neg$ tions. On the level of the interaction system involved, the market consist of swarms of forward-running conversations that include main dealing streams visible to all participants and various side sequences focused on information and personal exchanges. These clearly demarcated streams are embedded in the serial flow of contextual information and analysis delivered by Reuters and other firms that also scrolls down the screen.

Markets as continually composed, sequentially structured life-worlds can also be viewed in the aggregate; they appear as time-envelopes that move across time zones. This becomes relevant when a financial market is genuinely global, like the one for currencies - when the market covers the world by covering the clock. Globality here means time zone coverage of the developed world and its trading centers, rather than the geographical penetration of the earth's continents or the social penetration of its populations. Such a market flows in yet another sense: it moves in and out of time zones continually, and, as it does, it updates its features and positions.

Many of these features have to do with time and temporal coordina tion. For example, this market follows its own time, Greenwich Mean Time (see Zerubavel, 1982:12-13). Since the market has no central location, time is fixed to a particular coordinate of the globe to assure global identification of the correct transaction date. A further aspect is that global markets have 
their own calendars and schedules: dates and hours set for important economic announcements and for the release of periodically calculated economic indicators and data. These schedules structure participants' awareness and anticipation. The schedules 'anchor' market developments in national or regional economies' fundamental characteristics. Yet, as globally scheduled time points that punctuate and dramatize the ordinary temporal flow of events and observations, they also belong to the parallel time-world of global markets

The market arrives 'whole' at every new time zone and takes off 'whole' to the next one. When traders arrive at their desks in the morning in Tokyo and open their screens, they will find summary accounts of what happened before in the New York time zone - these accounts are encapsulated in closing rates, index values, volume statistics, intraday trading trends, etc. They will also find more qualitative summaries relayed to them by their contacts in the earlier time zone in their conversational dealing screens. Traders themselves make efforts to find out more about market developments in the earlier time zone: they listen to relevant news services at home, call friends, or contact them via the conversational dealing screens before and while they begin dealing. Most major institutional trading floors also have morning meetings where such information is reported, analyst's summaries prepared in another time zone are transmitted over intercoms, and on-floor analysts and economists relate their assessment of the situation. The European (London, Zurich, Frankfurt) and American (New York) time zones overlap by several hours (New York institutional trading starts at $8 \mathrm{am}$, which is $2 \mathrm{pm}$ Central European Time), during which the markets will not 'move on' immediately but will trade simultaneously until Europe closes the markets tend to get 'hectic' at these times just as they will be 'silent' when Tokyo is not yet very active and New York has closed. When the European closing time approaches, the same sort of summarizing and forwarding described earlier will take place. Traders in the same institution dealing in the same instrument may cooperate across time zones when longer-term contracts are involved (e.g. currency options) and positions cannot be closed at the end of a trading day. In this case the market's move to the next time zone may involve the transfer of a 'global book' - an electronic record of all contracts entered, including those added and structured in the forwarding time zone. Global books incorporate particular philosophies of trading whose content and adaptation to time-zone-specific circumstances will be discussed in similar beginning- and end-of-day global conversations between traders in different zones.

The market as aggregate 'flow' refers to these forwarding activities and to the aggregate positions and accounts that circle the globe. A flow 'architecture' refers to the support systems of these flows: the scopic systems which, through their performative and appresentational capabilities, enable a streaming market; the sequencing formats and automats that supplant network links, the structures of experience that develop and match flow. Flow architectures bring forth a level of integration in global fields that is 
based on the temporal intimacy of traders - they bring forth communities of time, as argued elsewhere (Knorr Cetina and Bruegger, 2002). Flow architectures are, presumably, not limited to financial markets; the temporalization of cultural diversity they imply, and their emergence in a global world, makes it likely that other areas (global terrorism, global science) will also develop similar characteristics.

Notes

1. The New York Stock Exchange Group merged with Euronext, the Paris-based European exchange in spring 2006 , creating the first (!) transatlantic exchange; it has since also formed alliances with the National stock Exchange of India and, as of January 2007, with the Tokyo Stock Exchange.

2. Messages were sometimes doubly coded - in Morse signals, and in a common language code in which words meant something different from everyday life - to safeguard and speed up communication.

3. Bucket shops were non-official brokerage houses, with varying financial power and reputation.

4. The Securities Exchange Act of 1933-34 introduces the mandatory recording of all regular lot transactions. In the case of the City of Chicago Board of Trade $\mathbf{v}$. Christie Grain \& Co., Justice Holmes wrote in his opinion that:

... the admitted fact that the quotations of prices from the market are of outmost importance to the business world, and not least to the farmers; so important, indeed, that it is argued here and has been held in Illinois that the quotations are clothed with a public use. (198 US 236)

5. The ticker recorded all regular lot transactions (i.e. in 100 shares or in multiples thereof) on the New York Stock Exchange. Odd lot transactions were not recorded until well into the 1960s (Securities Exchange Commission, 1963: ch. 6, part E, p. 91).

6. The introduction of cinema-like screens in the 1920 s and the switch to electronic tickers in the 1960 s can be counted among the upgradings undergone by this system.

7. Even after the introduction of the stock ticker, better price lists included only opening, closing, highest and lowest prices during a trading day. The tabulation of these prices required the kind of scrolling memory provided by the tape: while it was relatively easy to find out the opening and closing prices (situated at the ends of the tape), highest and lowest prices could be identified only by scrolling down the tape and comparing prices at different times of the day.

8. Charts of securities prices had existed since the early 19 th century, but visual ized at best monthly variations. Chart production was a specialized activity, requiring statistical knowledge, drawing accuracy, as well as data gathering skills (e.g. through archival research).

9. The study is based on ethnographic research conducted since 1997 on the trading floor of a major global investment bank in Zurich, New York and London, and in several others, for example, private and second-tier banks. Unlike other financial markets, the foreign exchange market is not organized mainly in 
centralized exchanges but derives from inter-dealer transactions in a global banking network of institutions; it is what is called an 'over-the-counter' market. See Knorr Cetina and Bruegger (2002) as well as Bruegger (1999) for a description of this research and of currency trading. For other trading rooms see Beunza and Stark (2005).

10. Networks are often contrasted with hierarchies in terms of their lack of a central coordinating power. Scopic media are not hierarchies and hence scoping must be seen as a third mechanism of coordination.

11. The general manager of Reuters at the time, Gerald Long, was able to claim by the early 1970s that the firm 'was operating the largest and most technically advanced news and information network in the world (Read, 1992: 290). This network had two main arteries: one crossed the Atlantic and Pacific (Tatpac), joining London to Singapore and Tokyo through Montreal, Sydney and Hong Kong; the other, Europlex, linked the main cities of the continent (London, Paris, Geneva, Frankfurt, The Hague and Brussels) in an 88-channel ring fed by dataspurs and leased teleprinter lines from other European cities. Reuters also leased 18 channels in a new round-the-world Commonwealth cable to Sydney via Canada in 1964 Europlex became operational in 1967. A great deal of the history of Reuter's transformation into a financial service firm has yet to be written.

12. Reuters proudly pronounced at the time that it was now operating a global stock exchange, since material was being fed into the system from all the main exchanges (Read, 1992: 298).

13. Reuters, Bloomberg and Telerate are the main providers of such systems. In 2001 , Reuters had more than 300,000 terminals installed world-wide in all markets and facilities, and Bloomberg more than 150,000. Revenue from leases of their systems amounted to approximately $\$ 2.5$ billion each at the end of 2001 . These figures were reported in the New York Times on 8 September 2002 (Barringer, 2002).

14. For Bergson, the immediate data of consciousness are a qualitative multiplicity - a heterogeneity of things (e.g. feelings) that are also temporal (Deleuze, 1991: $115-18)$.

15. This may explain why traders resort to notions of 'discipline' to try and recover some distance from market activities, which enables them to act in accordance with pre-established plans.

16. Dealing conversations are subject to institutional restrictions concerning language, response time, confirmation sequences, etc. that are not relevant to other conversations.

References

Abolafia, M. (1996) Making Markets: Opportunism and Restraint on Wall Street. Cambridge, MA: Harvard University Press.

Bank for International Settlement (2005) Triennial Central Bank Survey: Foreign Exchange and Derivatives - Market Activity in March 2004. Basel: BIS.

Barringer, F. (2002) 'Bloomberg, Without Bloomberg; Faces in an Industry in Retreat', New York Times 8 September: BU5.

Bauman, Z. (2000) Liquid Modernity. Cambridge: Polity Press.

Berman, M. (1982) All That is Solid Melts Into Air: The Experience of Modernity. London: Verso. 
Beunza, D. and D. Stark (2005) 'How to Recognize Opportunities: Heterarchical Search in a Trading Room', pp. $84-101$ in K. Knorr Cetina and A. Preda (eds) The Sociology of Financial Markets. Oxford: Oxford University Press.

Bruegger, U. (1999) 'Wie handeln Devisenhändler? Eine ethnographische Studie über Akteure in einem globalen Markt', unpublished dissertation, University of St Gallen, Switzerland.

Calahan, E.A. (1901) 'The Evolution of the Stock Ticker', The Electrical World and Engineer 37(6): $236-8$.

Castells, M. (1996) The Rise of the Network Society. New York: Harper and Row.

Clews, H. (1888) Twenty-eight Years in Wall Street. New York: Irving Publishing Co.

Cowing, C. (1965) Populists, Plungers, and Progressives: A Social History of Stock and Commodity Speculation. Princeton, NJ: Princeton University Press.

Deleuze, G. (1991) Bergsonism, H. Tomlinson and B. Habberjam trans. New York: Zone Books.

Downey, G. (2000) 'Running Somewhere between Men and Women: Gender in the Construction of the Telegraph Messenger Boy', Knowledge and Society 12: 129-52. Eames, F. (1894) The New York Stock Exchange. New York: Thomas G. Hall.

Fabian, A. (1990) Card Sharps, Dream Books, and Bucket Shops: Gambling in 19thcentury America. Ithaca, NY: Cornell University Press.

Gibson, G.R. (1889) The Stock Exchanges of London, Paris, and New York: A Comparison. New York: G.P. Putnam's Sons.

Hertz, E. (1998) The Trading Crowd: An Ethnography of the Shanghai Stock Market. Cambridge: Cambridge University Press.

Knorr Cetina, K. (2003) 'From Pipes to Scopes', Journal Distinction. Special Issue on Economic Sociology 7: 7-23.

Knorr Cetina, K. (2005) 'What are Financial Markets? Evidence from the Field of Global Currency Trading', paper presented at the $2004-5$ Harvard Colloquium Series, Department of Sociology, Harvard University, 25 February.

Knorr Cetina, K. (2007) 'Global Markets as Global Conversations', Text and Talk $27(5): 689-718$.

Knorr Cetina, K. and U. Bruegger (2002) 'Global Microstructures: The Virtual Societies of Financial Markets', American Journal of Sociology 107(4): 905-50.

Leyshon, A. and N. Thrift (1997) Money-Space: Geographies of Monetary Transformation. London: Routledge.

Medbery, J. (1870) Men and Mysteries of Wall Street. Boston: Fields, Osgood and Co.

Muniesa, F. (2000) 'Performing Prices: The Case of Price Discovery Automation in the Financial Markets', pp. $289-312$ in H. Kalthoff, R. Rottenburg and H.-J. Wagener (eds) Ökonomie und Gesellschaft. Marburg: Metropolis Verlag.

Podolny, J. (2001) 'Networks as the Pipes and Prisms of the Market', American Joumal of Sociology 107(1): 33-60.

Pratt, S. (1903) The Work of Wall Street. New York: D. Appleton and Co.

Preda, A. (2001a) 'The Rise of the Popular Investor: Financial Knowledge and Investing in England and France, 1840-1880', Sociological Quarterly 42(2): $205-32$. 
Preda, A. (2001b) 'The Enchanted Grove: Financial Conversations and the Marketplace in England and France in the 18th Century', Journal of Historical Sociology $14(3): 276-307$.

Preda, A. (2007) 'Where Do Analysts Come From? The Case of Financial Chartism', pp. 40-64 in M. Callon, F. Muniesa and Y. Millo (eds) Market Devices, Sociological Review vol. 55, monograph 2. Oxford: Blackwell.

Read, D. (1992) The Power of News: The History of Reuters. Oxford: Oxford University Press.

Sassen, S. (2001) The Global City. Princeton, NJ: Princeton University Press.

Schutz, A. and T. Luckmann (1973) The Structures of the Life-World. Evanston, IL: Northwestern University Press.

Securities Exchange Commission (1963) Report of the Special Study of Securities Markets of the Securities and Exchange Commission. Washington, DC: US Govern: ment Printing Office.

Selden, G.C. (1917) The Machinery of Wall Street. New York: The Magazine of Wall Street.

Smith, M.H. (1871) Twenty Years Among the Bulls and Bears of Wall Street. Hartford, CT: J.B. Burr and Hyde.

Smith, C. (1999) Success and Survival on Wall Street: Understanding the Mind of the Market. New York: Rowman and Littlefield.

Swedberg, R. (2003) Principles of Economic Sociology. Princeton, NI: Princeton University Press.

Urry, J. (2000) Sociology Beyond Societies: Mobilities for the Twenty-first Century. London: Routledge.

White, H. (2002) Markets from Networks: Socioeconomic Models of Production. Princeton, NJ: Princeton University Press.

Wyckoff, R. (1930) Wall Street Ventures and Adventures. New York: Harper and Brothers.

Zaloom, C. (2006) Out of the Pits: Traders and Technologyfrom Chicago to London. Chicago: University of Chicago Press.

Zerubavel, E. (1982) 'The Standardization of Time: A Sociohistorical Perspective', American Joumal of Sociology 88: $1-23$.

Karin Knorr Cetina is Professor of Sociology at the University of Konstanz, Germany, and teaches also at the University of Chicago. She does research on global currency markets.

Alex Preda teaches sociology at the University of Edinburgh. Currently he does research on online, anonymous financial markets. 